\title{
Cryptococcal empyema treated with tube thoracostomy and intrapleural fibrinolysis
}

\author{
Akshay Kohli ${ }^{1}$, Ashutosh Sachdeva ${ }^{2}$, Edward M. Pickering ${ }^{2}$ \\ ${ }^{1}$ Department of Internal Medicine, Medstar Washington Hospital Center, Washington; ${ }^{2}$ Department of Medicine, \\ University of Maryland School of Medicine, Baltimore, MD, USA
}

\begin{abstract}
A 55-year old woman with a history of relapsed T-cell ALL presented with right pleuritic chest pain and decreased breath sounds over the right hemithorax. Imaging of the chest showed loculated effusions. Tube thoracostomy was performed with intrapleural application of alteplase and dornase alpha over a 3day period. Repeat imaging demonstrated a marked decrease in the volume of the effusion. In most prior published cases of pleural cryptococcosis, surgical drainage was required in addition to prolonged antifungal agents. More than $50 \%$ of patients with cryp-
\end{abstract}

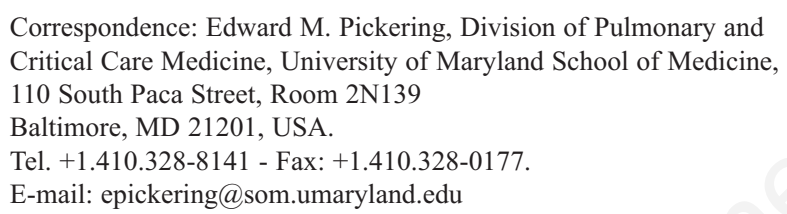

Key words: Empyema; cryptococcal; fungal, fibrinolytics; tube thoracostomy.

Contributions: AK, manuscript writing; EP, AS, review, editing, inclusion of data and contribution to case. All authors reviewed the manuscript and approved it.

Conflict of interest: AK, EP, AS declare no conflict of interest. EP, AS report grants, personal fees and non-financial support from Medtronic. AS reports grants and non-financial support from Olympus, personal fees from CSA Medical, personal fees from Pinnacle Biologics, outside the submitted work.

Funding: No funding was secured for this study

Conference presentation: This manuscript was previously presented as a case report abstract at the 2018 Chest Annual Meeting, San Antonio, TX, USA.

Received for publication: 26 February 2020.

Accepted for publication: 7 September 2020

${ }^{\mathbb{C}}$ Copyright: the Author(s), 2020

Licensee PAGEPress, Italy

Monaldi Archives for Chest Disease 2020; 90:1257

doi: 10.4081/monaldi.2020.1257

This article is distributed under the terms of the Creative Commons Attribution Noncommercial License (by-nc 4.0) which permits any noncommercial use, distribution, and reproduction in any medium, provided the original author(s) and source are credited. tococcal infection have severe underlying disease or immunodeficiency state making them high risk for surgery. This is the first case to our knowledge of cryptococcal empyema successfully treated with tube thoracostomy and intrapleural fibrinolysis.

\section{Introduction}

Empyema and complicated parapneumonic effusion usually result from bacterial invasion of the pleural space [1]. Although often associated with pneumonia, it can also develop after thoracic surgery or trauma. Complicated pleural effusion is objectively defined when pleural fluid $\mathrm{pH}$ drops to below 7.20 in addition to other less sensitive markers such as glucose below $60 \mathrm{mg} / \mathrm{dL}$ and Lactate dehydrogenase (LDH) more than three times the upper limit of normal [2]. Usually, an invasive procedure such as tube thoracostomy, is necessary for its resolution [3]. Mortality can be as high as $47 \%$ in hospital acquired infections [4]. Recent studies have noted a change in the bacteriology of empyema, possibly due to the widespread use of antibiotics as well as an increase in the incidence of fungal empyema [5,6]. Moreover, mortality in fungal empyema has been reported to be as high as $70 \%$ [5].

Although most patients previously have been treated with a combination of surgical drainage and antifungal therapy, the treatment of fungal empyema has not been protocolized and there is no consensus or guidelines for therapy $[3,5,7]$.

We present a case of fungal empyema in a woman previously diagnosed with T-cell acute lymphocytic leukemia (ALL) successfully treated with tube thoracostomy and intrapleural fibrinolytic therapy in addition to antifungal antibiotics.

\section{Case Report}

A 55-year old woman with a history of relapsed T-cell ALL presented with several days of fever, cough and right sided pleuritic chest pain. Computed tomography (CT) of the chest showed a small loculated right pleural effusion with adjacent consolidation of the right lower lobe. Broad spectrum antibiotics including meropenem were initiated. Ultrasound-guided thoracentesis yielded serous, slightly cloudy pleural fluid. Analysis of the fluid revealed a neutrophil-predominant exudative process with a $\mathrm{pH}$ of 7.0, glucose of $109 \mathrm{mg} / \mathrm{dL}$ and LDH of $260 \mathrm{IU} / \mathrm{l}$. The patient remained febrile with worsening pleuritic chest pain and a repeat $\mathrm{CT}$ revealed recurrence of the effusion with significant loculations (Figure 1). Due to the posterior location of dominant loculation as well as to guide optimal placement, ultrasound-guided tube thora- 
costomy via the Seldinger technique with a 14 French pigtail catheter was performed. Intrapleural instillation of alteplase (t-PA) $10 \mathrm{mg}$ and dornase alpha (DNase) $5 \mathrm{mg}$ concurrently twice daily over a 3-day period was initiated. For each instillation, the chest tube was clamped for $1 \mathrm{~h}$. Meanwhile, pleural fluid culture yielded C. neoformans and amphotericin B was initiated. Repeat imaging $24 \mathrm{~h}$ after the last fibrinolytic dose demonstrated a $76 \%$ decrease in the size of the effusion, measured volumetrically, with small residual loculation (Figure 2). Another attempt to drain the fluid was unsuccessful as the loculation was quite small and located para-scapular. Since the patient continued to improve clinically, no further pleural drainage was attempted. She was discharged approximately 3 weeks following her initial presentation on oral fluconazole. Repeat chest CT obtained 1-week post discharge showed complete resolution of the pleural effusion (Figure 3).

\section{Discussion}

Pleural infections are associated with high morbidity and mortality [4]. As noted above, complex pleural effusions and empyema can be fatal in as much as half of the patients who develop them. Early drainage of the pleural fluid and appropriate antibiotic therapy is fundamental to treatment. Prior to the MIST 2 trial, complex parapneumonic effusions and empyema often required surgical intervention for complete evacuation of the pleural space and control of infection [3]. Less invasive options such as antibiotics and drainage with tube thoracostomy fails in about a third of the patients $[8,9]$.

The use of intrapleural fibrinolytic therapy in the treatment of complex pleural effusions dates back to the 1950s when Tillet et al reported that intrapleural injection of streptokinase and streptodornase facilitated pleural drainage in patients with empyema [10]. Widespread use of these agents did not start until the 1990s when several observational studies reported the usefulness of fibrinolytics in the management of patients with loculated parapneumonic effusions [11,12]. Although this potential benefit of intrapleural

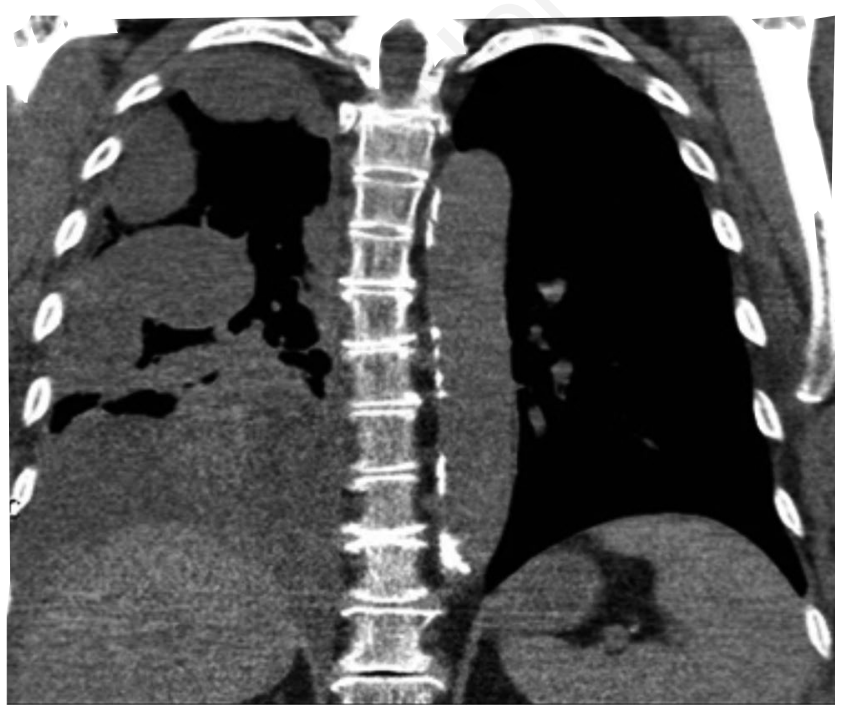

Figure 1. Sagittal CT showing loculated effusion before chest tube placement. fibrinolytics was not supported by the large First Multicenter Intrapleural Sepsis Trial (MIST1) and a subsequent meta-analysis $[13,14]$, Rahman and colleagues were able to show the benefits of intrapleural fibrinolytics (t-PA-DNase) in terms of fewer referrals for thoracic surgery and shorter hospital stay [8]. Subsequent studies have also shown successful management of complicated pleural space infections with t-PA and DNase $[9,15]$.

A recently published meta-analysis comparing surgical versus non-surgical (tube thoracostomy with or without intrapleural fibrinolysis) management for pleural empyema concluded that there was no difference in mortality between the groups. Video-assisted

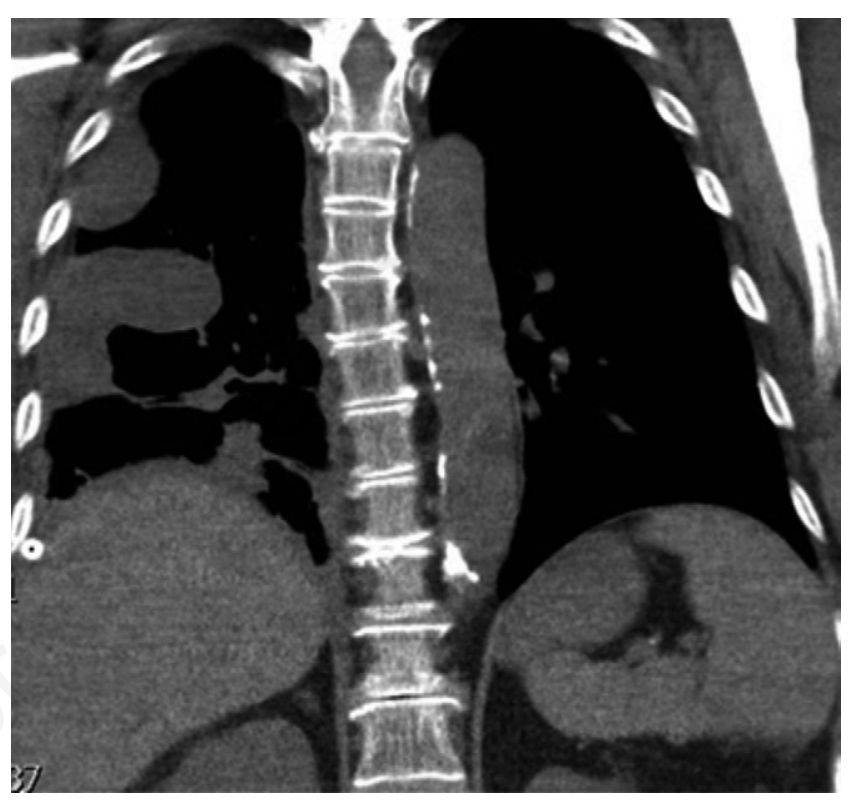

Figure 2. Repeat CT showing marked decrease in pleural fluid with some residual loculations.

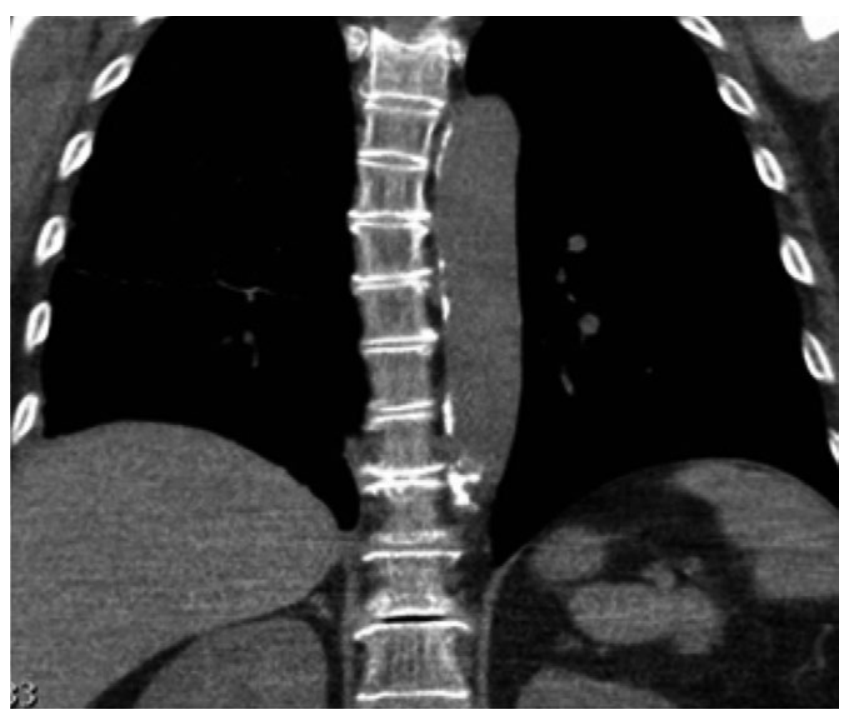

Figure 3. Follow-up CT-post 3 weeks showing complete resolution of the effusion. 
thoracoscopic surgery (VATS), however, was found to reduce the length of hospital stay compared to thoracostomy drainage only [16]. However, in this study, not all patients who underwent tube thoracostomy were treated with intrapleural fibrinolytics.

Although rare, the incidence of fungal empyema is increasing, and a significant number of cases have been reported in patients with underlying malignancy and severe immunocompromised state [5]. Most cases are due to Candida species.

Cryptococcus neoformans is a ubiquitous fungus found in soil. Humans are exposed to it by inhalation resulting in pulmonary infection which can range from asymptomatic to disseminated infection. Involvement of the pleural space is extremely rare [1719]. Most cases of fungal empyema have required surgical management with prolonged antifungal agents and there is a paucity of literature supporting intrapleural fibrinolytics [5,7]. Even in the MIST 2 trial, none of the reported cases involved documented fungal infections. Although recent advances in surgical management have reduced postoperative morbidity, surgical management has risk for complications and can often be limited by co-morbidities [20]. Moreover, patients at risk of and especially those who develop fungal pleural infections often have significant comorbidities including cancer, diabetes mellitus, long-term steroid treatment, hepatic cirrhosis, solid organ transplant, alcoholism, human immunodeficiency virus infection or recent surgery [5,7]. In circumstances such as this, when surgical management might be associated with high perioperative risks, tube thoracostomy and intrapleural fibrinolytics is a promising alternative. Close monitoring to assess for failure of therapy such as inadequate drainage and ongoing sepsis should still warrant surgical intervention after weighing the risks and benefits.

Our patient with a cryptococcal empyema and underlying Tcell ALL was treated successfully with tube thoracostomy and intrapleural fibrinolytic therapy.

\section{Conclusions}

Our case illustrates that this is a viable treatment option and should be considered in patients with high risk for perioperative morbidity.

\section{References}

1. Ahmed AEH, Yacoub TE. Empyema thoracis. Clin Med Insights Circ Respir Pulm Med 2010;4:1-8.

2. Light RW. Parapneumonic effusions and empyema. Proc Am Thorac Soc 2006;3:75-80.

3. Davies HE, Davies RJO, Davies CWH. Management of pleural infection in adults: British Thoracic Society pleural disease guideline 2010. Thorax 2010;65(Suppl 2):ii41-53.

4. Maskell NA, Batt S, Hedley EL, et al. The bacteriology of pleu- ral infection by genetic and standard methods and its mortality significance. Am J Respir Crit Care Med 2006;174:817-23.

5. Ko SC, Chen KY, Hsueh PR, et al. Fungal empyema thoracis: an emerging clinical entity. Ches. 2000;117:1672-8.

6. Pinnola A, Kuo Y-H, Sciarretta JD, et al. Bacteriology and comorbidities in patients requiring surgical management of empyema. Am Surg 2018;84:599-603.

7. de Vega Sánchez B, López Ramos I, Ortiz de Lejarazu R, Disdier Vicente C. Fungal empyema: An uncommon entity with high mortality. Arch Bronconeumol Engl Ed 20171;53:641-2.

8. Rahman NM, Maskell NA, West A, et al. Intrapleural use of tissue plasminogen activator and DNase in pleural infection. $\mathrm{N}$ Engl J Med 2011;365:518-26.

9. Piccolo F, Pitman N, Bhatnagar R, et al. Intrapleural tissue plasminogen activator and deoxyribonuclease for pleural infection. An effective and safe alternative to surgery. Ann Am Thorac Soc 2014;11:1419-25.

10. Tillett WS, Sherry S, Read CT. The use of streptokinasestreptodornase in the treatment of postneumonic empyema. J Thorac Surg 1951;21:275-97.

11. Jerjes-Sánchez C, Ramirez-Rivera A, Elizalde JJ, et al. Intrapleural fibrinolysis with streptokinase as an adjunctive treatment in hemothorax and empyema: a multicenter trial. Chest 1996;109:1514-9.

12. Bouros D, Schiza S, Patsourakis G, et al. Intrapleural streptokinase versus urokinase in the treatment of complicated parapneumonic effusions: a prospective, double-blind study. Am J Respir Crit Care Med 1997;155:291-5.

13. Maskell NA, Davies CWH, Nunn AJ, et al. U.K. Controlled trial of intrapleural streptokinase for pleural infection. N Engl J Med 2005;352:865-74.

14. Tokuda Y, Matsushima D, Stein GH, Miyagi S. Intrapleural fibrinolytic agents for empyema and complicated parapneumonic effusions: A meta-analysis. Chest 2006;129:783-90.

15. McClune JR, Wilshire CL, Gorden JA, et al. Safety and efficacy of intrapleural tissue plasminogen activator and DNase during extended use in complicated pleural space infections. Can Respir J 2016;2016:9796768.

16. Redden MD, Chin TY, van Driel ML. Surgical versus non-surgical management for pleural empyema. Cochrane Database Syst Rev 2017;3:CD010651.

17. Velagapudi R, Hsueh Y-P, Geunes-Boyer S, et al. Spores as infectious propagules of cryptococcus neoformans. Infect Immun 2009;77:4345-55.

18. Kerkering TM, Duma RJ, Shadomy S. The evolution of pulmonary cryptococcosis: clinical implications from a study of 41 patients with and without compromising host factors. Ann Intern Med 1981;94:611-6.

19. Gordonson J, Birnbaum W, Jacobson G, Nicholas Sargent E. Pulmonary cryptococcosis. Radiology 1974;112:557-61.

20. Farjah F, Symons RG, Krishnadasan B, et al. Management of pleural space infections: a population-based analysis. J Thorac Cardiovasc Surg 2007;133:346-51. 